\title{
APLICAÇÃO DO MÉTODO AHP PARA RANQUEAMENTO DOS PAÍSES AFRICANOS BENEFICIADOS PELO PROGRAMA DE AQUISIÇÃO DE ALIMENTOS (PAA) ÁFRICA NO PERÍODO DE 2014 A 2016
}

\author{
Eurico de Lima Figueiredo \\ Instituto de Estudos Estratégicos (INEST-UFF) \\ R. São João Batista, 1-187 - Centro, Niterói - RJ, 24020-005 \\ e_1_f@terra.com.br \\ Marcos dos Santos \\ Instituto Militar de Engenharia (IME) \\ Praça General Tibúrcio, 80 - Praia Vermelha - Urca - Rio de Janeiro - RJ \\ marcosdossantos_doutorado_uff@yahoo.com.br \\ Alexandre Rocha Violante \\ Escola de Guerra Naval (EGN) \\ Av. Pasteur, 480 - Urca, Rio de Janeiro/RJ, 22290-240 \\ alexandreviolante@id.uff.br \\ Larissa Lima \\ Instituto de Estudos Estratégicos (INEST-UFF) \\ R. São João Batista, 1-187 - Centro, Niterói - RJ, 24020-005 \\ limalarissa@id.uff.br \\ Lucas Ribeiro \\ Instituto de Estudos Estratégicos (INEST-UFF) \\ R. São João Batista, 1-187 - Centro, Niterói - RJ, 24020-005 \\ ribeirolucas@id.uff.br \\ Rodrigo Cravo \\ Instituto de Estudos Estratégicos (INEST-UFF) \\ R. São João Batista, 1-187 - Centro, Niterói - RJ, 24020-005 \\ rodrigocravo@id.uff.br
}

\section{RESUMO}

O presente artigo tem o intuito de analisar os impactos do Programa de Aquisição de Alimentos da África entre os anos de 2014 e 2016, financiado em parte pelo Brasil, utilizando o método Analytic Hierarchy Process para definir qual dos cinco países participantes foi o mais beneficiado. Baseia-se também na aproximação entre o Brasil e o continente africano como parceiros políticos e a influência do soft power brasileiro. Esta publicação entregará à sociedade brasileira análises sobre os recursos públicos investidos em parte dos programas e projetos humanitários, dentro da cooperação Sul-Sul, realizados pelo país.

Palavras-chave: Programa de Aquisição de Alimentos da África; Método AHP; Cooperação Sul-Sul; Programas Humanitários; Soft Power. 


\begin{abstract}
This article aims to analyze the impacts of the Africa Food Procurement Program between 2014 and 2016, funded in part by Brazil, using the Analytic Hierarchy Process method to define which of the five participating countries benefited most. It is also based on the rapprochement between Brazil and the African continent as political partners and the influence of Brazilian soft power. This publication will provide the Brazilian society with analyzes of the public resources invested in part of the humanitarian programs and projects, within the South-South cooperation, carried out by the country.
\end{abstract}

Keywords: Africa's Food Acquisition Program; AHP method; South-South Cooperation; Humanitarian programs; Soft Power.

\title{
Como Citar:
}

FIGUEIREDO, E. L.; SANTOS, M.; VIOLANTE, A. R.; LIMA, L.; RIBEIRO, L.; CRAVO, R. Aplicação do método AHP para ranqueamento dos países africanos beneficiados pelo Programa de Aquisição de Alimentos (PAA) África no período de 2014 a 2016. In: SIMPÓSIO DE PESQUISA OPERACIONAL E LOGÍSTICA DA MARINHA, 19., 2019, Rio de Janeiro, RJ. Anais [...]. Rio de Janeiro: Centro de Análises de Sistemas Navais, 2019.

\section{INTRODUÇÃO}

Em meio às diversas incertezas enfrentadas pelo mundo no início da década passada, a questão da fome e de como alimentar uma sociedade em constante crescimento era uma delas. Porém, um país se destaca quanto à pesquisa e o desenvolvimento de sua produção agropecuária: o Brasil. Desde o início da década de 1970, o país vem passando por uma modernização em seu programa de Segurança Alimentar graças à criação da Empresa Brasileira de Pesquisa Agropecuária. Nesse contexto, observou-se um enorme crescimento na produção de alimentos no país e o surgimento de programas de assistência social visando à erradicação da fome.

No entanto, enquanto alguns países prosperam e superam essa questão, outros seguem enfrentando a fome como principal obstáculo para atingir patamares mais elevados de desenvolvimento financeiro, econômico e, principalmente, social. Este é o caso da grande maioria dos países do continente africano, que têm a fome como um de seus maiores problemas humanitários. Faz-se necessário a criação e o financiamento de programas que fomentem e apoiem estes países, de maneira a ajudá-los a superar esta situação desumana. E é exatamente o que o Brasil tem feito a partir dos resultados positivos oriundos do processo de modernização da produção de alimentos, que culminou no já citado incremento da produção de alimentos no país.

Com este sucesso, a política externa brasileira decidiu, por meio do Itamaraty, exportar este modelo que vinha dando certo domesticamente, e a forma de fazê-lo foi através de doações realizadas a diversos programas humanitários que visam erradicar a fome, num desenho de cooperação internacional, sendo a sua principal contribuição feita à Organização das Nações Unidas para Alimentação e Agricultura (FAO).

Esse tipo de cooperação, a cooperação humanitária - utilizada para minimizar os efeitos de catástrofes naturais, epidemias, fome, dentre outras necessidades - é um dos os instrumentos comuns da cooperação internacional prestada pelo Brasil a Estados mais necessitados. 
Sobre cooperação, convém lembrar que o arcabouço teórico das relações internacionais se baseia em diversas e diferentes análises, distribuídas em várias linhas de pensamento. Segundo Axelrod e Keohane (1985), teóricos da escola institucional-liberal, cooperação é o processo de coordenação de políticas, através das quais atores ajustam seu comportamento às preferências existentes ou esperadas de outros atores. Para Morgenthau (1962), filósofo da escola realista, a cooperação é uma ação política, um instrumento de política externa de um Estado, a fim de ampliar seu poder, prestígio e ganhos econômicos no SI. Lumsdaine (1993), teórico da escola construtivista, afirma que a cooperação possui um envolvimento ético, de modo a se trabalhar em conjunto para promover mudanças benéficas e essenciais à sociedade. Já a teoria crítica ou marxista, representada por Wallerstein (1994) e Cox (1995a; 2007), a entendem como forma de expressão imperialista, o meio de dominação dos países mais poderosos sobre aqueles com menos recursos de poder, em uma relação de verticalidade que reforça a dominação e as desigualdades advindas do período colonial.

Portanto, pode-se afirmar, de acordo com Puente (2010), que a posição brasileira possui uma visão construtivista, ou seja, relaciona a cooperação com imperativos humanitários e compromissos éticos, utilizando-se do soft power como poder comportamental, fundamentando-se nas ideologias e nos aspectos culturais manifestos pelos Estados. Porém, a cooperação brasileira é, também, caracterizada por preceitos realistas e/ou institucionais-liberais: realista ao perceber que o Estado intenciona assegurar maior inserção, poder e influência no sistema internacional,; e institucional-liberal ao demonstrar que o poder e a circulação de informação, através das instituições, são as principais variáveis para a compreensão e manipulação desse sistema em prol dos interesses nacionais em relações ganha-ganha.

O tema a ser abordado neste artigo se refere ao programa Purchase from Africans for Africa (PAA África), implementado conjuntamente pela FAO e pelo PMA (Programa de Alimentos da ONU), em 2012. Este tema se faz extremamente importante justamente pela imensa importância do Brasil neste programa. Segundo a World Food Programme (WFP), o projeto foi um piloto inspirado no aprendizado brasileiro sobre compras institucionais de alimentos, sobretudo através do seu Programa de Aquisição de Alimentos (PAA). Ademais, ainda segundo a WFP, o PAA África é um projeto colaborativo realizado pela própria WFP, a FAO, e os governos do Brasil e do Reino Unido, em conjunto com os governos de cada país piloto (Etiópia, Malauí, Moçambique, Nigéria e Senegal). Esse tipo de cooperação internacional é chamado de cooperação triangular, ou seja, uma cooperação mista, formada por dois ou mais países em desenvolvimento e apoiada por recursos de países do Norte desenvolvido.

O presente artigo busca trazer dados, explicar e analisar todo esse processo, enriquecendo a literatura de relações internacionais sobre esse programa de cooperação humanitária internacional, ligado à cooperação trilateral ou triangular envolvendo o Brasil e também quanto aos seus impactos nos países pilotos.

Esta pesquisa será realizada com o auxílio do Método AHP (Analytic Hierarchy Process). O método AHP foi criado pelo Prof. Thomas L. Saaty, em 1980, e consiste na divisão do problema de decisão em níveis hierárquicos, facilitando, assim, sua compreensão e avaliação . Logo, o método mencionado é utilizado para analisar os impactos do PAA África nos cinco países piloto, de modo a verificar qual foi o país que apresentou o maior nível de melhora entre os anos de 2014 e 2016 (espaço de tempo no qual se deu a Fase II do programa, a fase mais recente, com os dados mais atualizados até a confecção deste artigo).

Uma vez obtida essa informação, pode-se estabelecer estudos específicos relacionados aos benefícios de tal projeto, não só no aspecto social, mas também no que tange à própria estratégia de inserção internacional empreendida pelo Brasil por meio da cooperação internacional ao desenvolvimento, traduzidas no aumento da participação 
brasileira em programas de proteção social.

\section{DESCRIÇÃO DO PROBLEMA}

A questão da fome, um problema humanitário, é global, e afeta uma grande parte da população mundial. Segundo dados divulgados pela FAO em 2018, através do relatório $E l$ Estado de La Seguridad Alimentaria y La Nutrición en el Mundo, de 2016 para 2017, o número de indivíduos passando fome no mundo aumentou de 815 milhões para 821 milhões. Os motivos para esta situação são os mais diversos: chuvas em excesso, secas, violência e conflitos armados etc.

Ainda segundo a Organização das Nações Unidas (ONU), em dados divulgados em 2017, cerca de 20 milhões de pessoas estão em risco de morrer de fome na África e no Iêmen. A organização afirma, também, que os seus esforços aumentaram, porém ainda faltam recursos. $\mathrm{O}$ destaque para tal fato é necessário, pois demonstra a extrema importância dos programas de ajuda humanitária direcionados ao continente africano, sobretudo os programas que visam erradicar a fome, como é o caso do PAA África.

A ONU caracteriza o PAA África como um projeto que visa ao investimento na merenda escolar de países africanos, num modelo em que os alimentos devem ser comprados de produtores locais. O programa é considerado inovador, pois combina a demanda de alimentos de escolas e outras instituições públicas, com o fornecimento agrícola de produtores familiares locais e organizações de agricultores. Esta iniciativa foi inspirada no Programa de Aquisição de Alimentos (PAA), empreendido pelo Brasil, e que gerou a modernização e o aumento da produção de alimentos no país. Ademais, trata-se de um programa piloto, iniciado em 2012, ainda vigente, e que age em cinco países piloto, sendo eles: Etiópia, Malauí, Moçambique, Nigéria e Senegal.

A questão da crescente e incessante fome no mundo, sobretudo na África, é de conhecimento global e alvo de vários esforços em nível internacional. Um dos países envolvidos nestes esforços é justamente o Brasil. Uma vez superado o problema da fome no país, o que ocorreu em 2014, de acordo relatório divulgado pela FAO, o Brasil tem aumentado cada vez mais o volume de suas doações monetárias pela cooperação triangular em projetos humanitários que visam à proteção social, como pode ser observado na Tabela 1 .

Tabela 1 - Evolução dos fundos trilaterais (em USD) 


\begin{tabular}{|c|c|c|c|c|c|c|c|c|c|}
\hline Partner & 2007 & 2008 & 2009 & 2010 & 2011 & 2012 & 2013 & 2014 & TOTAL \\
\hline FAO & & & 375.691 & 769.234 & 1.637 .674 & 2.098 .286 & 3.937 .450 & 9.371 .033 & 18.189 .368 \\
\hline Japan & & & 492.687 & 1.245 .532 & 10.273 .726 & 1.242 .009 & & & 13.253 .954 \\
\hline WFP & & & & & 800.000 & 2.000 .000 & 2.700 .000 & 2.100 .000 & 7.600 .000 \\
\hline Germany & & & & 954.867 & 507.112 & 6.063 .636 & & & 7.525 .615 \\
\hline UNODC & & & & 544.680 & 624.764 & 611.126 & 194.139 & 434.950 & 2.409 .659 \\
\hline Italy & & & 518.072 & 837.393 & 14.866 & 23.250 & & 18.300 & 1.411 .881 \\
\hline UNDP & & & & & & 488.044 & 520.403 & 213.799 & 1.222 .246 \\
\hline France & & 49.600 & & 261.312 & 170.348 & & & & 481.260 \\
\hline Canada & & 238.729 & & 157.058 & & & & & 395.787 \\
\hline UNICEF & & & & & & & & 45.500 & 45.500 \\
\hline Australia & & & & & & 34.480 & & & 34.480 \\
\hline Egypt & & & & 29.572 & & & & & 29.572 \\
\hline UK & & & & & 24.535 & & & & 24.535 \\
\hline Israel & & & & 20.650 & & & & & 20.650 \\
\hline Spain & 12.252 & & & & & & & & 12.252 \\
\hline $\begin{array}{l}\text { South } \\
\text { Korea }\end{array}$ & & & & & 9.640 & & & & 9.640 \\
\hline Total & 12.252 & 288.329 & 1.602 .340 & 10.704 .428 & 16.475 .850 & 13.717 .072 & 12.502 .814 & 16.559 .680 & 71.862 .765 \\
\hline
\end{tabular}

Fonte: United Nations Development Programme (UNDP, 2016)

Segundo o relatório Brazilian Triangular Cooperation in Social Portection: Contribution to the 2030 Agenda, divulgado em Outubro de 2016 pela United Nations Development Programme (UNDP), as contribuições do Brasil ao PAA África em doação monetária é direcionada ao FAO, que, por sua vez, repassa a verba para o programa em questão. Dessa maneira, estas doações podem ser mais bem alocadas, de acordo com as necessidades do momento. No caso do PAA África, o programa é financiado sobretudo pelas doações dos governos do Brasil e do Reino Unido.

A análise mais criteriosa dessa cooperação humanitária é fundamental para o entendimento dos resultados que estes programas apresentam na região. Sendo cinco os países-piloto, é extremamente importante verificar qual país tem se beneficiado mais do programa, de maneira não apenas a entender de que forma se dá esse benefício, em quais dimensões e até mesmo para uma futura análise a respeito da alocação de recursos, incrementando ainda mais os resultados obtidos pelo programa. Para uma análise mais exata, são usados os resultados mais recentes da Fase II do programa, obtidos através do relatório Phase II of the PAA Africa Progamme: results and lessons learned, divulgado pelo International Policy Center For Inclusive Grpwth (IPC-CG), em fevereiro de 2017.

$\mathrm{Na}$ Figura 1, apresentada a seguir, explica-se, através de um mapa mental, o processo realizado para eleger não apenas qual programa de proteção social financiado pelo Brasil deveria ser abordado neste artigo, mas, também, qual fase do programa deveria ser estudada e em que momento aconteceu a eleição dos critérios. 


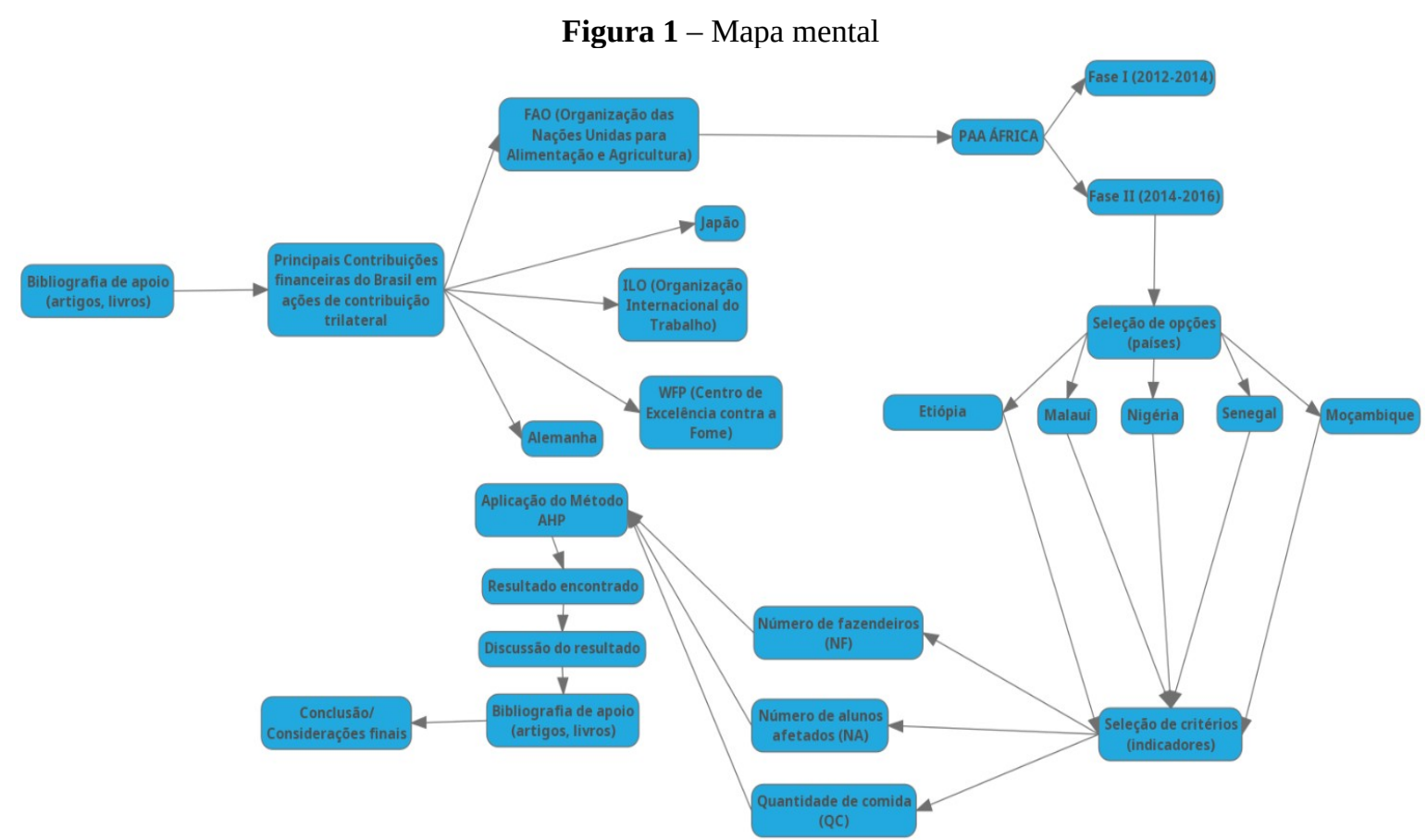

Fonte: Autores (2019)

\section{FUDAMENTAÇÃO TEÓRICA}

É desolador saber que se produz comida para alimentar a todos, mas ela não é justamente distribuída e por isso essa quantidade imensa de pessoas não têm acesso à uma dieta correta.

Visando melhorar este cenário, no Brasil das últimas décadas, a busca pela erradicação da fome começou a ser implementada pelo governo do presidente Cardoso (1995-2002), do Partido da Social Democracia Brasileira (PSDB). Essas políticas públicas foram incrementadas e mais bem desenvolvidas ao longo dos governos Lula (2003-10) e Rousseff (2011-16), do Partido dos Trabalhadores (PT), como pode ser constatado na panorâmica da reaproximação com o continente africano, a partir de meados dos anos 1970 .

O governo Geisel (1974-1979) antecipou um tanto quanto o final da Guerra Fria no hemisfério Sul, ao compreender que os conflitos e a cooperação não eram mais baseados pelo eixo Leste $v s$ Oeste, mas pelo eixo Norte (países desenvolvidos) vs Sul (países em desenvolvimento) e que essa mudança geopolítica proporcionava quadro de alianças sistêmicas. Com isso, são retomados os pilares da Política Externa Independente (PEI), lançada por San Thiago Dantas nos anos 1960, e que apresentara um retorno tímido nos governos de seus antecessores.

As mudanças de postura na política externa brasileira pode ser constatada, mais assertivamente, no reconhecimento, quase imediato, das independências dos Estados africanos, cujo processo de descolonização começara a ocorrer. A independência, em 1975, de Cabo Verde, São Tomé e Príncipe, e Angola foram bons exemplos disso. Ao reconhecer governos socialistas apoiados pela ex-URSS e por Cuba, a política do Pragmatismo Responsável ${ }^{1}$ não

\footnotetext{
${ }^{1}$ O Pragmatismo Responsável é definido pelo chanceler Azeredo da Silveira como: "pragmática, na medida em que buscamos a eficácia e estamos dispostos a procurar, onde quer que nos movam os interessas nacionais brasileiros, as áreas de convergência e as faixas de coincidência com os interesses nacionais de outros povos. Responsável, porque agiremos sempre na moldura do ético e exclusivamente em função de objetivos claramente identifica dos e aceitos pelo povo brasileiro" (SILVEIRA, apud GONÇALVES; MIYAMOTO, 1993, p.21).
} 
se deixou levar pelas reações internas e externas contrárias, principalmente, do Departamento of Defense estadunidense (DoD), alterando a imagem do Brasil na África.

$\mathrm{O}$ ressurgimento deste tema de low politcs está diretamente ligado com a reaproximação com a África. É interessante perceber que embora o Brasil tenha desenvolvido políticas para o continente africano em épocas anteriores, como na Política Externa Independente (PEI) nos anos 1960, e durante o governo Geisel (1974-79) a política dos governos Lula e Rousseff utilizou uma nova abordagem nas relações bilaterais e multilaterais entre o Brasil e as nações africanas.(ALMEIDA, 2014).

Em um crescente, com pequenos interregnos vistos por uma postura mais economicista e liberal do governo Collor (1990-92), a aproximação com a África continuou presente ao longo do governo Cardoso. Esta importava na medida em que suas relações multilaterais e bilaterais colaborassem para a inserção do Brasil no sistema internacional, por meio da liberdade política e econômica e com a cooperação através da integração e do comércio (LAMPREIA, 1996). Nessa leitura, os vieses econômicos e estratégicos caminhariam paripassu. Entretanto, sequer houve uma política integracionista com a África, em oito anos de governo. Cardoso percebeu, quase na metade de seu $2^{\circ}$ mandato, que os países do norte desenvolvido não procediam da forma como orientavam os demais países periféricos na gestão pública. Esse comportamento político, observado tanto nas decisões internas quanto nos foros multilaterais, levantavam dúvidas ao Brasil quanto ao acerto de suas políticas nacionais, implementadas até então (CERVO, 2013).

Lafer, ao assumir o MRE, em 2001, percebeu a oportunidade de recuperar os espaços perdidos no sistema internacional, chegando a ter, ao final de sua breve passagem na chancelaria, uma postura mais globalista. $\mathrm{O}$ caminho passara a ser o de relações bilaterais e multilaterais de mais alto nível com os países da América Latina, Caribe, da Ásia e da África.

Nesse novo período, os decisores da política externa brasileira perceberam que o continente africano buscava novos investimentos, agora sob regimes democráticos. Esta mudança na África deu-se, ainda, conforme movimentos pendulares, que permitiram alguns retrocessos, mas que alcançou êxito na maioria dos Estados. Assim, a África, coincidentemente, tornava-se mais atraente do que já era, com possibilidades de negócios e cooperação em todas as áreas, incluindo a área de defesa (GONÇALVES, 2014).

O governo Lula, em seu início, mostrou certa continuidade em algumas ações da política externa anterior, que já se transformara em uma política mais diversificada. Lula incrementou esse processo, aumentando o número de parcerias, principalmente com países emergentes, como China, Índia e Rússia, além dos Estados da África lusófona (VIGEVANI e CEPALUNI, 2011).

A diversificação de parcerias econômicas e político-estratégicas no tabuleiro geopolítico internacional trouxe um grau maior de autonomia, em uma perspectiva de não aceitação e enquadramento às diretrizes das potências hegemônicas, prevalecendo o imperativo de mudança, em um projeto de inserção internacional baseado nas relações Sul-Sul, sem abdicar do eixo vertical das relações com os países do Norte (VIOLANTE, 2017).

Cabe mencionar, ainda no governo Lula, que um dos maiores sinais de interesse do Brasil pela África ocorreu também com a inauguração de treze novas representações diplomáticas no continente (LEITE, 2011). O Brasil passou de dezoito para trinta embaixadas e de um para dois consulados gerais. Nesse sentido, o número de embaixadores em Brasília também aumentou de 16 para 25 em janeiro de 2003 e dezembro de 2006 . No viés comercial, pôde ser observado também que, entre 2003 e 2006, as exportações para a África aumentaram em $315 \%$ e as importações deste continente aumentaram 307\%, o que representou um crescimento de US\$6 bilhões para US\$15 bilhões (RIBEIRO, 2007). 
Com isso, a África, novamente, passou a ser prioridade nas relações bilaterais e multilaterais. Essa política africana teve continuidade também no governo Rousseff. De acordo com Saraiva (2014), a política externa de Rousseff conferiu mais atenção às relações Brasil-África do que avançou em direção à construção de uma identidade política e estratégica no continente sul-americano.

A forte crise econômica que se instalou a partir de 2014 não fez com que ocorresse solução de continuidade e interrupção da prioridade alcançada pela África em projetos humanitários, o que pode ser corroborado com as palavras de seu último chanceler, Mauro Vieira (jan/2015 a mai/2016), sobre o momento vivido na cooperação internacional: "ajustes conjunturais podem incidir momentaneamente [...], mas não alteram nossa noção de prioridades. A África foi, é, e continuará a ser uma prioridade absoluta da política externa brasileira" 2 . Desse modo, a ABC priorizou a execução e a finalização dos projetos firmados com os países parceiros e optou por diminuir o número de projetos iniciados, haja vista os cortes progressivos em seu orçamento (DA COSTA, 2015).

Dentro da moldura temporal dessa pesquisa, de 2014 a 2016, para suprir a falta de recursos e reduzir custos, motivados pela forte crise econômica, priorizou-se a cooperação trilateral, ao se estabelecerem parcerias com países desenvolvidos, entre eles, mais intensamente, os EUA, Alemanha e Japão. O diretor da ABC (até julho de 2015), o embaixador Fernando Marroni de Abreu, reiterou que essa nova estratégia de expansão de projetos trilaterais era muito maior do que a contenção de custos, pois "representava um avanço em relação à cooperação Norte-Sul, sendo, portanto, menos paternalista" (DE ABREU, 2013, p.13). A cooperação trilateral é um tipo de cooperação interessante, mas é preciso ter cuidado para que imposições de países terceiros tirem o modus operandi de como a cooperação brasileira é realizada, oferecendo autonomia e atendendo aos desejos do país recebedor.

Portanto, dentro dessa panorâmica da política externa e da cooperação internacional com África nas duas últimas décadas, a exportação do modelo que vinha sendo desenvolvido domesticamente passou a ser visto como uma forma de colaboração internacional. O Brasil participa ativamente da cooperação internacional para o desenvolvimento em áreas muito diversas, mas com especial ênfase na agricultura e na alimentação. Nesse campo, o Brasil se apresenta como uma referência internacional devido ao relativo êxito de programas internos (Bolsa Família, Fome Zero etc.) e à possibilidade de transferência externa dessas experiências (MUÑOZ e CARVALHO, 2015).

O aumento dessa participação internacional teve incentivos orçamentário, legislativo, organizacional, participativo e principalmente no discurso oficial. Cada um deles funcionou como um elo de transmissão através do qual as novas orientações domésticas foram projetadas na ação internacional do Brasil e impulsionaram seu soft power.

No que diz respeito à projetos de combate à fome, dentro da política externa brasileira, pode se afirmar que as mudanças na orientação política dos governos do PT foram significativas, uma vez que os presidentes foram inspirados por "paradigmas" contraditórios - visões de mundo que orientam a ação diplomática (CERVO e BUENO, 2016).

Finalmente, no aspecto da Segurança Alimentar e Nutricional, o Brasil conseguiu promover importantes políticas de fortalecimento do direito humano à alimentação no continente africano. Sabe-se que das mais de 800 milhões de pessoas que passam fome no mundo, mais de 30\% são africanas (FAO, 2018).

Contudo, a visão de segurança alimentar ainda é considerada insuficiente por aqueles que veem, na alimentação, não só uma necessidade a ser coberta para a

\footnotetext{
${ }^{2}$ Brasil recua e reduz projetos de cooperação e doações para a África- Patrícia Melo na coluna Mundo. Folha de São Paulo em 22 mar. 2015. Disponível em: <http://www1.folha.uol.com.br/mundo/2015/03/1606466-brasil-recua-e-reduz-projetos-de-cooperacao-e-doacoes-para-a-africa.shtml.>. Acesso em: 22 set. 2016.
} 
sobrevivência, mas também um indicador de dignidade e sociabilidade (MUÑOZ e CARVALHO, 2015).

\section{PROPOSTA DE SOLUÇÃO}

Após a fundamentação teórica que possibilitou uma análise qualitativa quanto à cooperação com a África nas últimas décadas, de forma mais generalista, faz-se necessário verificar o quanto o projeto humanitário do PAA África, de forma mais estrita aos países piloto, pode ser quantificado. Assim, a partir dos dados obtidos desse programa, é possível discriminar os principais elementos a serem utilizados na análise que é feita a seguir, para a obtenção de um resultado mais detalhado sobre os impactos do PAA África em relação aos países piloto.

I- Método de análise utilizado: Método AHP;

II- O objetivo da utilização deste método: eleger o país mais beneficiado pelas ações empreendidas pelo PAA África durante a Fase II do programa, empreendida entre 2014 e 2016;

III - Opções: se trata dos cinco países piloto onde foram empreendidas as ações do programa, sendo eles a Etiópia, o Malauí, Moçambique, Nigéria e Senegal;

IV - Critérios: para realizar esta análise, foram escolhidos três critérios, sendo o primeiro o número de fazendeiros $(\mathrm{NF})$, o segundo a quantidade de comida (QC, em toneladas métricas), e o terceiro o número de alunos afetados. Os dados referentes a tais critérios foram obtidos através do relatório Phase II of the PAA Africa Progamme: results and lessons learned, divulgado pelo International Policy Center For Inclusive Growth (IPCCG), em fevereiro de 2017;

V - O emprego do Método AHP tem papel fundamental, sobretudo porque são comparados critérios de diferentes unidades de medida, o que é totalmente possível utilizando tal método. Ademais, fornece uma espécie de "base científica" para o resultado, tornando-o mais "correto" e eficaz, de maneira a não comprometer a análise.

Conforme já explicado anteriormente, o Método AHP é utilizado para ajudar na tomada de decisão a respeito dos países piloto do programa PAA África. Sabe-se que são cinco os países africanos onde estas ações estão sendo empreendidas (sendo eles a Etiópia, o Malauí, Moçambique, Nigéria e Senegal), porém, o objetivo é eleger o país mais beneficiado pelo programa durante a Fase II, empreendida entre os anos de 2014 e 2016. Essa informação é de extrema importância, não apenas para que se possa identificar e analisar mais a fundo os resultados do programa durante esta fase, mas até mesmo para que sejam realizados estudos em relação à alocação de recursos, de maneira a equilibrar os resultados.

A seguir, inicia-se a aplicação do método, passo a passo.

a) Em primeiro lugar, para iniciar a aplicação do Método AHP, deve-se construir a hierarquia dos critérios, como pode ser observado na Figura 2;

Figura 2 - Construção da Hierarquia dos Critérios 


\section{Seleção do país africano mais impactado pelo PAA África, entre os anos 2014 e 2016}

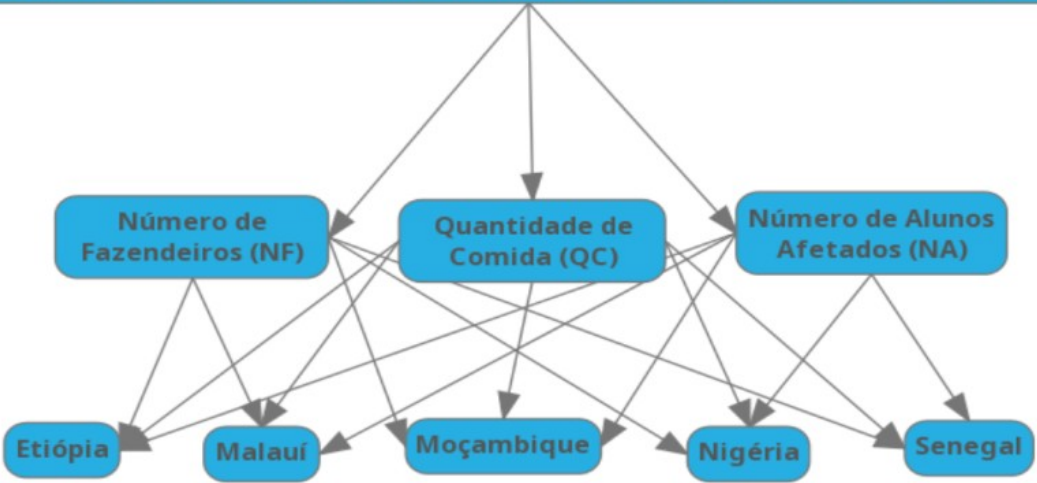

Fonte: International Policy Center For Inclusive Grpwth (IPC-CG, 2017).

b) Depois, desenha-se a Matriz de Decisão, conforme apresentada na Tabela 2. Para a construção da matriz, são utilizados os dados obtidos no relatório Phase II of the PAA Africa Progamme: results and lessons learned, divulgado pelo International Policy Center For Inclusive Grpwth (IPC-CG), em fevereiro de 2017;

Tabela 2 - Matriz de Decisão

\begin{tabular}{|c|c|c|c|}
\hline & NÚMERO DE FAZENDEIROS & QUANTIDADE DE COMIDA (MT) & NÚMERO DE ALUNOS AFETADOS \\
\hline ETIÓPIA & 2.815 & 333,45 & 9.700 \\
\hline MALAUÍ & 3.773 & 361 & 8.557 \\
\hline MOÇAMBIQUE & 672 & 40,57 & $0^{2}$ \\
\hline NIGÉRIA & 7.738 & 1776,8 & $8.788^{3}$ \\
\hline SENEGAL & 1.000 & 186 & 2065 \\
\hline
\end{tabular}

Fonte: International Policy Center For Inclusive Grpwth (IPC-CG, 2017).

${ }^{1} \mathrm{MT}=$ Toneladas Métricas; é uma unidade de massa igual a 1.000kg.

$2 \mathrm{Na}$ Nigéria, as compras realizadas pelo PAA África foram usadas para suplementar o programa de alimentação escolar da WFP (World Food Programme), e não foram distribuídas em escolas específicas.

${ }^{3} \mathrm{O}$ número de escolas beneficiadas flutuou durante a Fase II, devido a restrições orçamentárias no programa de alimentação escolar da WFP. Por esse motivo, escolhemos o menor número apresentado no relatório, já que este representa o número final de beneficiados.

c) A seguir, realiza-se os cálculos necessários para que a Matriz de Decisão seja normalizada, virando um Matriz de Decisão Normalizada. Vale ressaltar que esses cálculos são divididos e organizados por coluna;

d) Após realizados os cálculos, desenha-se a Matriz de Decisão Normalizada, apresentada na Tabela 3 a seguir, utilizando os resultados obtidos no item c. É importante salientar que a soma dos itens de cada coluna deve ser igual a 1 ;

Tabela 3 - Matriz de Decisão Normalizada 


\begin{tabular}{|c|c|c|c|}
\hline & NÚMERO DE FAZENDEIROS & QUANTIDADE DE COMIDA (MT) & NÚMERO DE ALUNOS AFETADOS \\
\hline ETIÓPIA & 0,18 & 0,12 & 0,26 \\
\hline MALAUÍ & 0,24 & 0,13 & 0,27 \\
\hline MOÇAMBIQUE & 0,04 & 0,02 & 0,23 \\
\hline NIGÉRIA & 0,48 & 0,66 & 0 \\
\hline SENEGAL & 0,06 & 0,07 & 0,24 \\
\hline
\end{tabular}

Fonte: Autores (2019)

e) Após este processo, é necessário que se construa uma Matriz de Ponderação. Aqui, é realizada uma comparação, par a par, de cada um dos elementos em um determinado nível hierárquico. Assim, cria-se uma matriz de decisão quadrada, por meio de uma escala pré-definida, denominada Escala Fundamental de Saaty (Tabela 4), em que se atribui pesos aos critérios escolhidos, representando a preferência em relação aos elementos comparados. O processo pode ser observado na Tabela 5;

Tabela 4 - Escala Fundamental de Saaty

\begin{tabular}{|c|c|c|}
\hline Intensidade & Definição & Explicaçăo \\
\hline 1 & Igual importância & $\begin{array}{l}\text { Dois elementos contribuem } \\
\text { igualmente para o objetivo }\end{array}$ \\
\hline 3 & Importância fraca & $\begin{array}{c}\text { O julgamento favorece levemente } \\
\text { a um dos elementos }\end{array}$ \\
\hline 5 & Importância forte & $\begin{array}{l}\text { O julgamento favorece fortemente } \\
\text { a um elemento }\end{array}$ \\
\hline 7 & Importância muito forte & $\begin{array}{l}\text { A dominância de um elemento } \\
\text { pode ser demonstrada }\end{array}$ \\
\hline 9 & Importância absoluta & $\begin{array}{c}\text { A evidência que favorece um dos elementos } \\
\text { é da maior ordem possível de afirmação }\end{array}$ \\
\hline 1,1 a 1,9 & $\begin{array}{l}\text { Quando d } \\
\text { a adição de }\end{array}$ & $\begin{array}{l}\text { ois elementos estão próximos, } \\
\text { um decimal pode ser apropriada }\end{array}$ \\
\hline
\end{tabular}

Fonte: SAATY (1991)

Tabela 5 - Matriz de Ponderação 


\begin{tabular}{|c|c|c|c|}
\hline & $\begin{array}{c}\text { NÚMERO DE } \\
\text { FAZENDEIROS }\end{array}$ & QUANTIDADE DE COMIDA (MT) & NÚMERO DE ALUNOS AFETADOS \\
\hline NÚMERO DE FAZENDEIROS & 1 & $1 / 5$ & $1 / 3$ \\
\hline QUANTIDADE DE COMIDA (MT) & 5 & 1 & 3 \\
\hline NÚMERO DE ALUNOS AFETADOS & 3 & $1 / 3$ & 1 \\
\hline
\end{tabular}

Fonte: Autores (2019)

f) Em sequência, realizam-se os cálculos necessários para que a Matriz de Ponderação seja normalizada. Esses cálculos são divididos e organizados por coluna;

g) Após a realização dos cálculos, desenha-se a Matriz de Ponderação Normalizada, utilizando os resultados obtidos no item $\mathrm{f}$. A soma dos itens de cada coluna deve ser igual a 1. A matriz pode ser observada na Tabela 6;

Tabela 6 - Matriz de Ponderação Normalizada

\begin{tabular}{|c|c|c|c|}
\hline & NÚMERO DE FAZENDEIROS & QUANTIDADE DE COMIDA (MT) & NÚMERO DE ALUNOS AFETADOS \\
\hline NÚMERO DE FAZENDEIROS & 0,11 & 0,13 & 0,08 \\
\hline QUANTIDADE DE COMIDA (MT) & 0,56 & 0,65 & 0,69 \\
\hline NÚMERO DE ALUNOS AFETADOS & 0,33 & 0,22 & 0,23 \\
\hline
\end{tabular}

$\Sigma=1 \quad \Sigma=1 \quad \Sigma=1$

Fonte: Autores (2019)

h) O próximo passo é a obtenção da média aritmética de cada linha da Matriz de Ponderação Normalizada, obtida no item g. É importante ressaltar que a soma do resultado da média aritmética de cada linha deve ser igual a 1 . O processo pode ser observado abaixo;

$$
\begin{aligned}
& \text { NÚMERO DE FAZENDEIROS (NF): } \\
& N F=\frac{0,11+0,13+0,08}{3}=0,11 \\
& \text { QUANTIDADE DE COMIDA (QC): } \\
& Q C=\frac{0,56+0,65+0,69}{3}=0,63 \\
& \text { NÚMERO DE ALUNOS AFETADOS (NA): } \\
& N A=\frac{0,33+0,22+0,23}{3}=0,26
\end{aligned}
$$

$$
\Sigma=1
$$

i) Com os resultados obtidos no item h, desenha-se o Vetor Prioridade. Assim, deve-se 
ordenar cada critério de acordo com a sua importância/prioridade. Para isso, o maior número é considerado o critério mais importante, e o menor número, o menos importante. O Vetor Prioridade é apresentado a seguir;

$$
\vec{v}_{p_{c}}=\left[\begin{array}{c}
0,11 \\
0,63 \\
0,26
\end{array}\right] \Rightarrow \text { NA } \Rightarrow{ }^{30 \text { Colocado }}
$$

j) Consequentemente, realiza-se a multiplicação da Matriz de Decisão Normalizada e do Vetor de Prioridade, conforme a Tabela 7. Esse processo dá origem a uma nova matriz, denominada Vpa, discriminada na Tabela 8;

Tabela 7 - Matriz de Decisão Normalizada x Vetor Prioridade

$$
\vec{v}_{\mathrm{pa}}=[\text { MATRIZ DE DECISÃO NORMALIZADA }] \times\left[\vec{v}_{\mathrm{pc}}\right]
$$

MATRIZ DE DECISÃO NORMALIZADA:

\begin{tabular}{|c|c|c|c|}
\hline & NÚMERO DE FAZENDEIROS & QUANTIDADE DE COMIDA (MT) & NÚMERO DE ALUNOS AFETADOS \\
\hline ETIÓPIA & 0,18 & 0,12 & 0,26 \\
\hline MALAUÍ & 0,24 & 0,13 & 0,27 \\
\hline MOÇAMBIQUE & 0,04 & 0,02 & 0,23 \\
\hline NIGÉRIA & 0,48 & 0,66 & 0 \\
\hline SENEGAL & 0,06 & 0,07 & 0,24 \\
\hline
\end{tabular}

Fonte: Elaborado pelos Autores (2019)

\begin{tabular}{|c|c|c|c|c|c|}
\hline $\overrightarrow{\boldsymbol{v}_{p_{a}}}=$ & & & & & \\
\hline ETIÓPIA & 0,02 & + & 0,08 & + & 0,07 \\
\hline MALAUÍ & 0,03 & + & 0,08 & + & 0,07 \\
\hline MOÇAMBIQUE & 0,00 & + & 0,01 & + & 0,06 \\
\hline NIGÉRIA & 0,05 & + & 0,42 & + & 0,00 \\
\hline SENEGAL & 0,01 & + & 0,04 & + & 0,06 \\
\hline
\end{tabular}

Tabela 8 - Matriz Vpa.

Fonte: Elaborado pelos Autores (2019)

k) Por fim, o último passo consiste na soma de cada linha da Matriz Vpa. Por esse cálculo, 
obtém-se o resultado tão esperado: a linha que obtiver a maior soma indica a opção vencedora, ou seja, a linha que tiver a maior soma representa o país que mais foi beneficiado pelo programa PAA África durante a sua Fase II, empreendida entre os anos de 2014 e 2016. O resultado é obtido na Tabela 9.

Tabela 9 - Resultado do Método AHP.

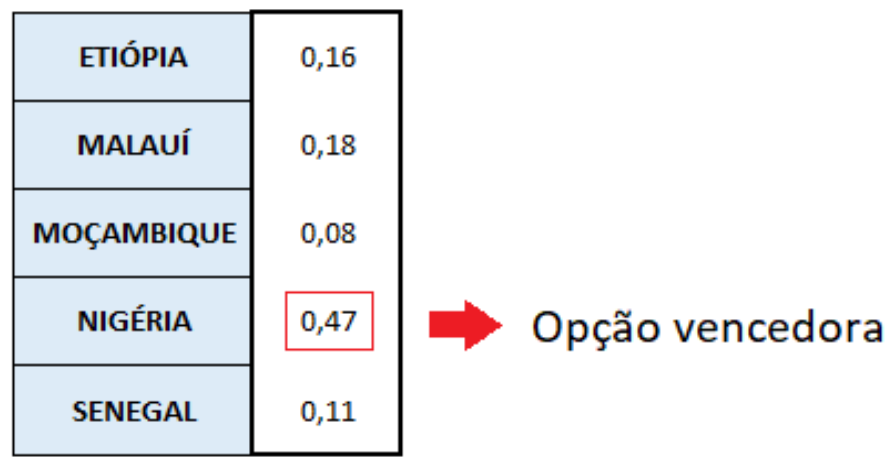

Fonte: Elaborado pelos Autores (2019)

\subsection{RESULTADOS ALCANÇADOS}

Conforme pode se observar nos resultados numéricos apresentados após a aplicação do Método AHP, a opção vencedora foi a Nigéria. Desta forma, o Método AHP indica que, a partir dos critérios utilizados (número de fazendeiros, quantidade de comida em toneladas métricas, e número de alunos afetados), o país mais beneficiado na Fase II do programa PAA África, empreendida entre os anos de 2014 e 2016, foi a Nigéria.

Ou seja, dentre os países pilotos, sendo eles Etiópia, Malauí, Moçambique, Nigéria e Senegal, a Nigéria foi o país cujos impactos do programa foram mais significativos, afetando de maneira positiva e em larga escala a população deste país.

Também pode se observar através da aplicação do Método AHP que o segundo país mais beneficiado foi o Malauí, seguido da Etiópia e do Senegal. Por fim, Moçambique foi o país menos beneficiado, devido ao impacto do PAA África ter sido menos significativo, foi Moçambique.

\section{DISCUSSÃO DOS RESULTADOS}

Os resultados alcançados e expostos causaram surpresa inicial haja vista que a Nigéria não possuía dados referentes aos alunos que se beneficiaram da merenda escolar advinda do incremento da produção de alimento. Acreditava-se, por inferência, que a Etiópia seria reconhecida como a mais beneficiada pela distribuição de valores na tabela. Há que se perceber, entretanto, que a Nigéria é um dos países com maior poder relativo em África, mas com desigualdades proporcionalmente grandes.

A partir disso, percebe-se a importância dos pesos dados aos critérios. Eles foram coerentes, visto que o Programa de Aquisição de Alimentos significa a disponibilização de comida. Então, via-se a necessidade da produção de comida possuir um peso maior frente aos demais.

Outro ponto que vale a menção é o fato de Moçambique ter conquistado o último lugar, pois, logicamente, devido às questões culturais semelhantes que são compartilhadas 
com o Brasil, acreditava-se que Moçambique talvez se privilegiasse, já que a análise qualitativa apontou certa priorização da África lusófona nas relações internacionais ao longo dos governos Lula e Rousseff, ou seja, dentro da moldura temporal dessa pesquisa (2014 a 2016). Vale ressaltar também que não necessariamente o país que obteve menores números foi aquele que menos se beneficiou do programa, pois nem todos os países que ali estão possuem o mesmo número de pessoas em situação de risco alimentar.

Tendo as constatações em vista, o método AHP proporcionou uma ponderação dos resultados de acordo com o que mais importava para o programa e permitiu que fosse possível transformar diferentes formatos de critérios em um dado numérico calculável e comparável. Este método se mostrou muito eficaz e correspondeu perfeitamente às expectativas do trabalho aqui apresentado.

\section{CONSIDERAÇÕES FINAIS}

A motivação para a realização desta pesquisa é entregar ao Instituto de Estudos Estratégicos (INEST), à Universidade Federal Fluminense (UFF), e à sociedade em geral um resultado claro e independente dos impactos da exportação do modelo de segurança alimentar e nutricional brasileiro através da cooperação trilateral, entre os anos de 2014 e 2016, que influenciaram na inserção do país em uma nova posição no cenário internacional. Para isto, foram analisadas, de forma ampla, a política externa baseada na cooperação internacional dos governos das últimas décadas (Geisel, Collor, Cardoso, Lula e Rousseff), os dados do relatório Phase II of the PAA Africa Progamme: results and lessons learned, divulgado pela One Pager, em Fevereiro de 2017, e também o Método AHP, de maneira a analisar os impactos desta fase do programa entre os cinco países piloto (sendo eles Etiópia, Malauí, Moçambique, Nigéria e Senegal). A análise pelo método AHP se mostrou primordial para a avaliação dos resultados gerados por tal programa, podendo ser utilizado em análises estratégicas para o incremento de políticas públicas eficientes para, além de beneficiar os países recipiendários, buscando, por exemplo, uma melhor e mais justa alocação de recursos entre os países citados, também atinge os objetivos nacionais de inserção internacional do Brasil.

O combate à fome e o acesso ao alimento faz parte dos objetivos da ONU para o mundo e este trabalho entrega à sociedade o que o Brasil vem fazendo para que essa meta seja alcançada, pelo menos no que diz respeito ao continente africano. A presente pesquisa tem sua importância evidente visto que o conhecimento de seus resultados pode ser interessante para a sociedade como um todo, além de incentivar a criação de mais projetos inspirados nesse modelo, ou promover melhorias neste projeto. Afinal, a fome deve ser combatida para além-fronteiras e o direito humano à alimentação de qualidade é uma obrigação global.

Ademais, o método AHP proporciona corroborar ou criticar análises qualitativas, por meio de respostas matemáticas ao objeto de estudo, sendo ferramenta importante dentro da multidisciplinaridade que a área dos Estudos Estratégicos apresentam.

\section{REFERÊNCIAS BIBLIOGRÁFICAS}


ALMEIDA, Paulo Roberto. Uma política externa engajada: a diplomacia do governo Lula, Rev. bras. polit. int. vol.47 no.1, Brasília, 2004.

AXELROD, Robert e KEOHANE, Robert O. Achieving Cooperation under Anarchy: Strategies and Institutions. World Politics, V.38, N.1 (oct.,1985). Cambridge University Press, p.226-254. Disponível em: <http://www.jstor.org/stable/2010357>. Acesso em: 12 abr. 2015.

BRASIL RECUA E REDUZ PROJETOS DE COOPERAÇÃO E DOAÇÕES PARA A ÁFRICA- Patrícia Melo na coluna Mundo. Folha de São Paulo em 22 mar. 2015. Disponível em: <http:/www1.folha.uol.com.br/mundo/2015/03/1606466-brasil-recua-e-reduz-projetos-de-cooperacao-e-doacoes-para-a-africa.shtml.>. Acesso em: 22 Ago. 2019.

CERVO, Amado Luiz e BUENO, Clodoaldo. História da política exterior do Brasil. FUNAG, Brasília, 2002.

CERVO, Amado Luiz. Relações internacionais da América Latina: de 1930 aos nossos dias. São Paulo: Saraiva, 2013.

COX, Robert W. Critical Political Economy. In: HETTNE, B. (Org.). International Political Economy: under global disorder. Nova Scotia: Fernwood Books, 1995.

COX, Robert W. Gramsci, hegemonia e relações internacionais: um ensaio sobre o método. In: GILL, Stephen (Org.). Gramsci, Materialismo Histórico e Relações Internacionais. Tradução Dinah de Abreu Azevedo. Rio de Janeiro, Editora UFRJ, 2007.

DA COSTA, Cristiana Martinello. Cooperação Técnica Brasil-África no Governo Dilma Rousseff - Expansão ou Retração? Tese de Doutorado. Universidade de Brasília (UnB), 2015.

DE ABREU, Fernando José Marroni. A Evolução da Cooperação Técnica Internacional no Brasil/The Evolution of International Technical Cooperation in Brazil. Mural Internacional, V.4, N.2, p.3-16, 2013. Disponível em: $<$ http://www.e-publicacoes.uerj.br/index.php/muralinternacional/article/view/ 8658>. Acesso em: 12 abr. 2016.

GONÇALVES, Williams e MIYAMOTO, Shiguenoli. Os Militares na Política Externa Brasileira. Estudos Históricos, V.6, N.12. Rio de Janeiro: CPDOCFGV, 1993.

LAMPREIA, Luiz Felipe. A Política Externa do Governo FHC: continuidade e renovação, Revista Brasileira de Política Internacional, V.42, N.2, p.5-17, 1998. Disponível em: $<$ http://www.scielo.br/pdf/rbpi/v41n2/v41n2a01.pdf >. Acesso em: 26 fev. 2016.

LEITE, Patrícia Soares. O Brasil e a Cooperação Sul-Sul em três momentos de política externa: os governos Jânio Quadros/João Goulart, Ernesto Geisel e Luiz Inácio Lula da Silva. Brasília, Funag, 2011.

LUMSDAINE, D. Moral Vision in International Politics. The Foreign Aid Regime 19491989. Princeton: Princeton University Press, 1993. 
MALUF, Renato S.,SANTARELLI, Mariana e PRADO, Veruska. A cooperação brasileira em segurança alimentar e nutricional: determinantes e desafios presentes na construção da agenda internacional. Rio de Janeiro, 2014.

MORGEnTHAU, H. A Political Theory of Foreign Aid. The American Political Science Review, V.LVI, N.2, p.301-309, 1962.

MUÑOZ, Enara Echart e CARVALHO, Tássia Camila de Oliveira. A cooperação sul-sul brasileira com a África no campo da alimentação: uma política coerente com o desenvolvimento. IN: Caderno CRH. Salvador, 2016.

ORGANIZAÇÃO DAS NAÇÕES UNIDAS. PAA ÁFRICA: investindo em merenda escolar para países africanos, vídeo. ONU, Nova York, 2016. Disponível em: < https://nacoesunidas.org/paa-africa-investindo-em-merenda-escolar-nos-paises-africanosvideo/>. Acesso em: 02 dez. 2018.

ORGANIZAÇÃO DAS NAÇÕES UNIDAS PARA ALIMENTAÇÃO E AGRICULTURA (FAO). Na África e no Iemên, 20 milhões de pessoas estão em risco de morrer de fome. FAO, Roma, 2017. Disponível em: <https://nacoesunidas.org/na-africa-e-no-iemen-20milhoes-de-pessoas-estao-em-risco-de-morrer-de-fome/>. Acesso em: 02 dez. 2018.

ORGANIZAÇÃO DAS NAÇÕES UNIDAS PARA ALIMENTAÇÃO E AGRICULTURA (FAO); FUNDO INTERNACIONAL DE DESENVOLVIMENTO AGRÍCOLA (FIDA); PROGRAMA MUNDIAL DE ALIMENTOS (WFP); ORGANIZAÇÃO MUNDIAL DE SAÚDE (OMS); FUNDO DAS NAÇÕES UNIDAS PARA A INFÂNCIA (UNICEF). El Estado de la Seguridad Alimentaria y la Nutrición en el Mundo: Fomentando la Resiliencia Climatica en Aras de la Seguridad Alimentaria y la Nutrición. FAO, Roma, 2018. Disponível em: < http://www.fao.org/3/I9553ES/i9553es.pdf> . Acesso em: 02 dez. 2018.

PANORAMA DA SEGURANÇA ALIMENTAR E NUTRICIONAL. FAO, América Latina $e$ Caribe, 2018. Disponível em <http://www.fao.org/3/a-i6977o.pdf $>$. Acesso em: $02 \mathrm{dez}$. 2018.

PUENTE, Carlos Alfonso Iglesias. A Cooperação Técnica Horizontal Brasileira como instrumento da Política Externa: a evolução da cooperação técnica com países em desenvolvimento - CTPD - no período 1995-2005. Brasília: FUNAG, 2010. Disponível em: $<$ http://www.funag.gov.br/biblioteca /dmdocuments/0715.pdf $>$. Acesso em: 16 jul. 2015.

RIBEIRO, Cláudio Oliveira. Relações político-comerciais Brasil-África (1985-2006). Diss. Universidade de São Paulo, 2007.

SAATY, T. L. Método de Análise Hierárquica. São Paulo: McGrawn-Hill, 1991.

SARAIVA. Miriam Gomes. Balanço da Política Externa de Dilma Rousseff: perspectivas futuras? Relações Internacionais (R:I), N.44, p.25-35, 2014.

UNITED NATIONS DEVELOPMENT PROGRAMME (UNDP). Brazilian Triangular Cooperation in Social Protection: Contribution to the 2030 agenda. UNDP, Nova York, 2016. 
\%20Publications $/ 11874 \% 20-\% 20$ Brazilian $\% 20$ Triangular $\% 20$ cooperation $\% 20 \mathrm{in} \% 20$ social \%20protection $11 \mathrm{Web} \% 20$ Version(1).pdf $>$. Acesso em: $02 \mathrm{dez} .2018$.

VIGEVANI, Tullo e CEPALUNI, Gabriel. A Política Externa Brasileira: a busca da autonomia de Sarney a Lula. São Paulo: Editora Unesp, 2011.

VIOLANTE, Alexandre Rocha. Política Externa, de Defesa e Cooperação Sul-Sul como Grande Estratégia do Brasil na África Ocidental: Um Estudo de Caso sobre Cabo Verde e São Tomé e Príncipe. Dissertação. Mestrado em Estudos Estratégicos do Programa de PósGraduação em Estudos Estratégicos (PPGEST) do INEST-UFF. Niterói; RJ. 2017. 366p.

WALLERSTEIN, I. The Modern World-System. Capitalist agriculture and the origins of the European world-economy itz the 16th. century. New York: Academic Press, 1994.

WORLD FOOD PROGRAMME (WFP). Lessons Learned from the Purchase from Africans for Africa Iniciative. WFP, Roma, 2015. Disponível em: $<$ https://www.wfp.org/purchaseprogress/news/blog/lessons-learned-purchase-africans-africa-initiative $>$. Acesso em: 02 dez. 2018. 